\title{
An Update on Smell and Sensuality
}

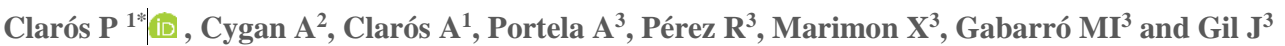

${ }^{1}$ Clarós Clinic. Barcelona, Spain.

${ }^{2}$ Scholarship Clarós Foundation. Barcelona, Spain.

${ }^{3}$ Universitat Internacional de Catalunya. Bioengineering Institute of Technology. Barcelona. Spain.

*Corresponding Author: Clarós P, Clarós Clinic. Barcelona, Spain.

Received Date: June 06, 2021; Accepted Date: August 20, 2021; Published Date; September 27,2021

Citation: Clarós P, Cygan A, Clarós A, Portela A, Pérez R, Marimon X, Gabarró MI and Gil J. (2021). An Update on Smell and Sensuality. J. Clin otorhin. 3(4); DOI:10.31579/2692-9562/036

Copyright: (C) 2021 Clarós P, This is an open-access article distributed under the terms of the Creative Commons Attribution License, which permits unrestricted use, distribution, and reproduction in any medium, provided the original author and source are credited.

\begin{abstract}
When thinking of smell, we usually consider it only as one of the five senses. Compared to the rest of senses, smell has been underestimated. By conducting a research, we will be able to discover how mistaken we are. The human sense of smell is more powerful than it's usually given credit for and plays a major role in human health and behavior than many experts in the field are aware of the sense of smell is present in our daily activities and, depending on the gender, perception may differ, as well as from the anatomical structure of the olfactory organ between genders to the stimulus of the odor. The fragrances determine our everyday food choices, places where we choose to spend with our life partner. Scents can determine our sexual behavior, in building infantparent connection and create our habits as well. It can also warn us against the selection of food, persons, also death. In this case, the loss of smell can be related with an olfactory organ dysfunction, but as well can have an endocrine, genetic or psychical basis. The olfactory dysfunction can change our habits and basically our whole life. It is irrefutable that while talking about smell which we consider as one of the senses, we can talk about sensuality which broadly covers the relationship between smell and perception of reality. Sensuality in a general sense can be defined as the perception of the surrounding things through the senses, as sensory pleasure, and unlike sexuality, which can be translated as the reception of biological, psychological and physical stimuli.
\end{abstract}

Aim of the study: Currently all of our senses are mostly well known. We are trying to consider the topic from many different sides to make ourselves more and more advanced. We are trying to unite a couple of subjects to prove that we can connect one with another to explore how advanced our organism is. In this research we are trying to look closely at the two different topics and glue them together. Trying to improve and update the connection between the sense of smell and sensuality. This is possible due to the relationship between the smell and the part of our brain responsible for memories and memory, i.e. the limbic system. In this way, we can process the aroma stimulus into memories, we associate smells with specific situations, places, people or things [1].

Therefore, the objectives we have in this study are the following: The nose as an olfactory organ and the anatomical differences as to structure; the olfactory system is strictly connected with the sense of smell; sex, as a gender, something that make us different from each other; physical and psychological disorders and influence of smell.

Taking into consideration the amount of work and research on the sense of smell and the still uncertain issues related to it, it is certain how important it is for life and science to fully understand its properties. Over time, with the development of science and technology, there is an increasing wish to learn about such a complicated machine as the human body.

Material and methods: In the first part of this research, we will gather all the information that is commonly available so far in the international bibliography, as well as the achievements and utilities obtained to date. Following we will analyse all the new concepts that exist on the topic of sense of smell in connection with sex and sensuality, also how the smell can change due to various disorders and try to summarise it based on the latest research.

Keywords: smell; olfaction; sex; gender; sensuality; sexuality

\section{Introduction}

\section{1 - Nasal organ and sexuality}

Nasal shape and gender
Visually, the nose is the most prominent part of the human face, being the main gate to the respiratory system, responsible for several important functions, smell, and taste, among others. Indisputably, we can say that the 
nasal structure is a complex organ. It consists of a nasal skeleton, which houses the nasal cavity [2].

The size, angle, shape and type of nose are a signature indicating race, age and sex. Anthropometric parameters vary with age, sex, and ethnic background, and several authors have attempted to document normative values, which may serve as references. These parameters provide types of beauty, because it is at the center of the face [3]. From the well-known analyses, the ideal shape for a woman's nose should be slightly upturned, and male noses should be well defined and strong. Instead of having a slope, they should be straight. Human noses can also have a wide array of shapes and sizes due to injuries [4].

Nowadays, thanks to the development of plastic and aesthetic surgery, the availability of methods to improve the appearance of the external nose is wide. It is dictated by the significant population demand. In addition to improving the respiratory function, people want to improve their nose appearance. It may be related to injuries that have caused deformation as well as the desire to improve the attractiveness of the nose in accordance with the prevailing canons and improve self-esteem.

Evolution was a likely factor in the differences between the differences in the shape and appearance of the nose. According to the researchers, ethnic changes in the shape of the nose were dependent on the climate in which the race lived and evolved. People living in cool and harsh climates, the nose is narrower, so that inhaled air has time to warm and moisturize, while in hot and humid climates, we observe wide noses with large nostrils [5].

There are also differences in anatomical structure, where we can distinguish changes in the thickness of the alar cartilages of the nose depending on race, from small and thin in the African group to large and thick in Afro-Indian. [6].

Nowadays, these differences tend to dissapear due to the reduction of cultural differences and interracial relationships, so the necessity to adapt to the surrounding environment is not necessary. In addition, the still valid canons of human appearance and the imposed exponents of beauty push people to resemble their dream ideal. Hence, many people undergo surgery or aesthetic medicine treatments. Referring to the indicated differences in the structure of the nose, it significantly influences the course of the procedure. It is very well known by the facial plastic surgeons the importance of modifying the shape of the nose in a different way according to gender, age and race. Due to the differences in type and age, each surgery must be selected individually, especially in children before the end of nose growth [7]. Each procedure entails a risk of failure, such as infection, loss of smell, or dissatisfaction with the result.

\section{2 - The olfactory system}

The olfactory sense is one of the biological senses responsible for our sense of smell and determines our everyday functionality.

Olfaction begins when the odorant molecules enter the nasal cavity while breathing, sniffing or from the oral cavity, while chewing. During this process, the molecules pass through the nasal valve area on their way to the headspace above the mucus-coated olfactory receptors. These molecules interact with olfactory receptors, which are part of a family of G-protein coupled receptors. Stimulation of these receptors causes the production of second messenger receptors, which leads to the opening of ion channels and the generation of action potentials in olfactory receptor cells [8].
This produces a change in the membrane potential at the tip of the olfactory receptor cell that in turn creates an electronic signal that flows along the axons of the olfactory neurons to the olfactory bulb [9].

The olfactory bulb is a structure located in the forebrain of vertebrates that receives neural input about odors detected by cells in the nasal cavity. The axons of olfactory receptor cells extend directly into the olfactory bulb, where information about odors is processed. Here, the axons projecting from the olfactory receptor cells via the olfactory nerve terminate where they converge on the dendrites of olfactory bulb neurons in small clusters called glomeruli (glomerulus in plural) which consist of the axons of several thousand olfactory receptor neurons converging on the dendrites of a small collection ( 40 to 50 ) of olfactory bulb neurons (Figure 1). Each glomerulus only receives input from one type of odorant receptor, but it is capable to detect multiple odorants [8]. The signal from the olfactory bulb reaches along the olfactory tract to the olfactory cortex of the brain by the transduction, which is located in the temporal lobe and throughout the limbic system (Figure 2).

Studies suggest that in the human body, there are around 12 million olfactory receptor cells and they can detect approximately 10.000 odours (Table I).

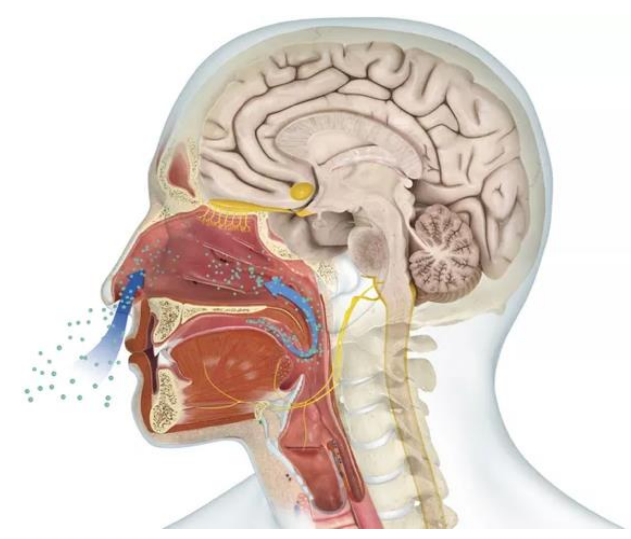

Figure 1. Anatomy of the human olfaction

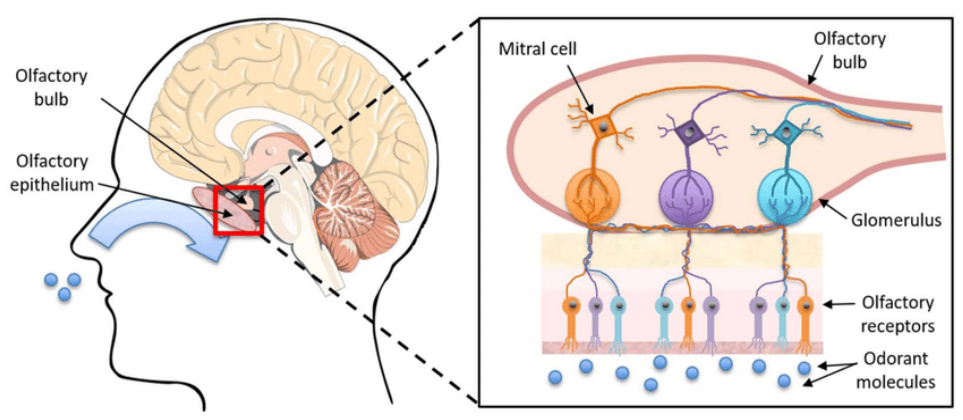

Figure 2. The olfactory system. 


\begin{tabular}{|c|l|}
\hline Nose & While breathing, it humidifies, filters, and warms the air inside the nose. \\
\hline Nasal cavity & Cavity divided by the nasal septum into left and right passages. It is lined with mucosa. \\
\hline $\begin{array}{c}\text { Olfactory } \\
\text { epithelium }\end{array}$ & $\begin{array}{l}\text { Specialized type of epithelial tissue in nasal cavities that contains olfactory nerve cells and receptor } \\
\text { nerve cells. These cells send impulses to the olfactory bulb. }\end{array}$ \\
\hline $\begin{array}{c}\text { Cribriform } \\
\text { plate }\end{array}$ & $\begin{array}{l}\text { A porous extension of the ethmoid bone, which separates the nasal cavity from the brain. Olfactory } \\
\text { nerve fibers extend through the holes in the cribriform to reach the olfactory bulbs. }\end{array}$ \\
\hline $\begin{array}{c}\text { Olfactory } \\
\text { nerve }\end{array}$ & $\begin{array}{l}\text { Nerve (first cranial nerve) involved in olfaction. Olfactory nerve fibers extend from the mucous } \\
\text { membrane, through the cribriform plate, to the olfactory bulbs. }\end{array}$ \\
\hline $\begin{array}{c}\text { Olfactory } \\
\text { bulbs }\end{array}$ & Bulb-shaped structures in the forebrain where olfactory nerves end and the olfactory tract begins. \\
\hline $\begin{array}{c}\text { Olfactory tract } \\
\text { Olfactory } \\
\text { cortex }\end{array}$ & $\begin{array}{l}\text { Band of nerve fibers that extend from each olfactory bulb to the olfactory cortex of the brain. } \\
\text { the olfactory bulbs. }\end{array}$ \\
\hline
\end{tabular}

\section{3 - Vomeronasal Organ (VNO, Jacobson's organ)}

The vomeronasal organ, known as chemoreception organ, is part of the olfactory organ, in many animals and in humans, located on the anteroinferior portion of the nasal septum. In reptiles, it is an organ of smell, while in humans it is best visualized in newborns, but as it matures, its function disappears. It contains receptors of pheromones from the V1R, V2R and V3R families, stimulating the secretion of gonadotropin, and its main function in animals is to improve communication [10].

In humans, the organ contains specialized olfactory cells, or esthesiocytes, and is still a controversial topic considering, for example, the influence of nasal septum surgery on changing sexual behavior [11].

\section{4 - Differences of the sense of smell determine by the gender and age.}

Gender differences in olfaction have been a topic of interest for many researchers since almost the 19th century. There is an interest in discovering how much our senses can interact with our body.

This subsection must be parted because of the commonly distinguished genders, hormonal participation in an organism growth, specific disorders as also the psychological background.

The differences start when the gender is determined by its physiological meaning. Men's and women's physiological development is a background to differences between. In Oliveira-Pinto [12] research, an attempt was made to demonstrate the dimorphism of the olfactory bulb in men and women on the basis of postmortem examination, which showed a slight difference in the weight of the olfactory bulb in both sexes, but at the same time a significant difference in the number of cells: 16.2 million in women and 9.2 million in men.

When we grow up not only our sense of smell changes, but also our physical odor. From being a newborn, a child, becoming a teenager, an adult when getting old, our fragrance changes, so is our possibility to recognize them.

Our scent is functioning since birth. According to a 2017 study by Zhang [13], newborn infants locate their mother's nipples by the breast odor. Familiar smells are easier to identify for young children as well as for adults. This specially occurs in children. In a study carried out on adults and children, an attempt was made to prove a greater sense of smells with a similar molecular structure. Another example of the differentiation of odors in children and in adolescence is the work from 2017 Novakova [14]. Citing research from other years, it shows that the perception of smells in children evolves from recognizing friendly smells to discriminating them as pleasant and unpleasant smells in relation to puberty and learning. Odor tests were carried out in children depending on their age. It was found that in girls it was determined by their age whether someone smelled good or bad. The older the girls are, more likely they were to describe men's fragrance as more pleasant, than woman's. Depending on the degree of maturity; more mature girls were able to describe the smell of children as more pleasant than that of adults. Simultaneously with age, people from outside the family showed more pleasant smells in older children [14].

\section{5 -The effect of contraception on the sense of smell}

Use of women's birth control methods affects the olfactory performance. There are many forms of hormonal contraception used for birth control. Although each form has differences, they work the same way. All of them have an influence on woman's hormone levels during ovulation by inhibiting the follicular development. The hormonal contraception is the most popular method of birth control. The most common are combined oral contraceptives. Hormonal contraceptives contain estrogen and progestin hormones and the dose depends on what kind of contraceptives is chosen. The hormones influence human physiology and can make a big difference. The issue of hormonal contraceptives influence on the women's body is well known, understood, such as skin changes, and menstrual pain reduction. In addition, there are changes during the ovarian cycle in the women's body that appears mostly in all body systems. The coincidence between olfaction and the ovarian cycle is well known. We know for sure that during ovulation, most changes appear. It has been proved that women have higher sensitivity of smell during ovulation, and they describe odors differently.

Referring to the Caruso study from 2001, a difference was found in rhinomanometry in women using oral contraception compared to the luteal and follicular phase of the normal menstrual cycle. At the same time, the deviations were so small that they did not significantly impair the smell [15]. In 2013, Renfro ]16] refers in his research to the results presented in the Lundstrom 2006 study [17], in which the author noted the differences in the perception of smells depending on the phase of the ovarian cycle and when taking oral contraceptives. They showed clearly that women before ovulation were more sensitive to androstenedione than to phenyl-

ethyl alcohol (PEA - the scent of roses); while women using contraception were quite the opposite [18].

In a 2016 study from the University of Graz, Kollndorfer [19], the duration of contraceptive use and the dose of ethinyl estradiol were taken into consideration. The study showed, based on the Sniffin test, that women 
using a lower dose of oral contraception have a higher TDI than women taking the higher dose and not using contraception.

Taking into account the above references, it may be concluded that to some extent, hormones affect our sense of smell. It is important to inform the patient about possible olfactory complications, because despite everything, the topic is not fully understood.

\section{6 - The influence of pregnancy on olfaction.}

Pregnancy is another factor that distinguishes gender. It is a fact that women have the possibility to be pregnant; it is then obvious it is not a fully natural state. There are many changes going on in a woman's body during pregnancy and each pregnancy can proceed in a different manner, due to hormone changes. While using contraceptives, the hormones are kept on equal level, during pregnancy, the hormone levels fluctuates.

Many changes occur in women during pregnancy and one of these is definitely, a heightened sense of smell and inconvenient odors. In addition, they suffer from stuffy nose, mostly on the mucosal edema during the third trimester, sometimes even in the first and third. In 2017, ENT updates reported the effects of pregnancy on the olfactory function in women, summarizing changes in the perception of smells, mainly, intolerance to certain substances. In addition, edema changes in the mucosa, in the first and third trimesters. The smell abnormalities were almost absent at postpartum period. The demonstrated changes in the perception of smells are associated with nausea and vomiting during pregnancy [20].

According to the research done by Fornazieri et all, in 2019 [21], the results of studies in pregnant and puerperal women, and non-pregnant women, were taken into consideration. The examination was performed using the University of Pennsylvania Smell Identification Test (UPSIT). In women without rhinitis, regardless of the condition, no significant changes in the perception of smell were found. Of course, the presence of rhinitis results in an influence on the results. From the examination with different kind of substances, only clove and coffee were smelled differently. Most changes occurred in the third trimester of pregnancy. In conclusion, there was no permanent olfactory influence and differences between women in gestation, post-partum and non-pregnant.

Fornazieri [21] shows ratings of the pleasantness and intensity of common odors, such as coffee, smoke, clove and baby powder smells between medical examinations, pregnant, and postpartum women. It showed that only coffee and clove were rated differently between pregnant and nonpregnant women; coffee, as less pleasant in the first trimester and more intense in the puerperium, second and third trimester, and clove as less pleasant in the second trimester.

Our body is exposed to many factors that may impair its proper functioning. Environmental factors, diseases, lifestyle, personal variability and age may influence it. There is no doubt that our body ages with age. Many vital functions and systems are weakened. This process also affects the sense of smell. The number of neurons in the olfactory epithelium is reduced, so that the olfactory stimulus is not able to fully stimulate the olfactory cortex. In the study conducted by Sorokowska, 2014 [22], it provided research on the influence of sex and age on odor identification. The test was performed in people of different age and sex, from babies to people after 70. After analyzing the test, it was shown that the perception of odors in the elderly is comparable to that in young children, while the best perception is more visible in young adults and adults.

\section{7 - Genetic diseases and the sense of smell}

The sense of smell can be influenced by many factors, including genetic. Over the years, genetic diseases have been identified. One of the symptoms is lack of the sense of smell. Anosmia can also be the result of a mutation in the genes that leads to a dysfunction of the olfactory organ without additional symptoms, but it is a very rare condition. Most anosmia is the result of acquired diseases of the upper respiratory tract, allergies, chronic sinusitis or after trauma.

Turner Syndrome (TS) is a condition associated with the lack of some or all of the $\mathrm{X}$ chromosome and it is the most common genetic disorder in women. In the clinical picture, we observe short stature and underdevelopment of the internal genital organs. It can lead to estrogen deficiency, primary amenorrhea, and delayed puberty. The disease may be accompanied by other disturbances in the functioning of the body. However, it is often the case that women with Turner Syndrome (TS) are unaware of it, and may function normal and have children. Referring to the study by Ros (2012) [23] which described the conducted study aimed at assessing and comparing the sense of smell in women with TS and women named as healthy, it showed no deviations.

Kallman's syndrome is another type of disorder, which may be genetic, as well as spontaneous, in the clinical picture of which there is impairment or anosmia coexisting with hypogonadotrophic hypogonadism. This disorder is most common in men. In this syndrome, GnRH (gonadotropinreleasing hormone) neurons move abnormally from the nasal poster to the center of the brain [24].

\section{8- Neurodegenerative diseases and smell level}

Sense of smell is influenced mainly by neurodegenerative diseases. The most common diseases in this group, affecting the largest number of people, are certainly Alzheimer's disease and Parkinson's disease. Disturbances in the body's sensory functions may present as early symptoms at the onset of the disease (Table II).

The ailment condition that affects most people is Alzheimer's disease (AD). So far, there is no cure for it. Bathini et al. [25] in 2019, set out to present the olfactory dysfunction as one of the first early symptoms of AD. They presented the pathologies in the sense of smell, included in the table below [25]. 


\begin{tabular}{|c|c|c|c|}
\hline $\begin{array}{l}\text { Anatomy } \\
\text { superior turbinate } \\
\text { middle turbinate }\end{array}$ & $\begin{array}{l}\text { Neuropathology } \\
\text { Olfactory epithelium: } \\
\beta \text {-Amyloid aggregates } \\
\text { Degeneration of OSN } \\
\text { Occlusion of the foramina } \\
\text { Olfactory bulb: } \\
\text { Reduction in bulb volume } \\
\text { Prominent tauopathy } \\
\text { Diffused } \beta \text {-amyloid aggregates } \\
\text { Increase in DA neurons } \\
\text { Axonal loss in OT } \\
\text { NFTs and core plaques in AON } \\
\text { Olfactory cortices: } \\
\text { Tauopathy in olfactory tuberculum, PC, } \\
\text { AMG, EC } \\
\text { Amyloidosis and atrophy in OFC } \\
\text { Thalamocortical relay: } \\
\text { Thalamic hypometabolism } \\
\text { Degeneration of the medial thalamus }\end{array}$ & $\begin{array}{l}\text { Pathogen: Host } \\
\text { C.Pneumoniae : ApoE\&4 } \\
\text { Spirochete } \\
\text { HSV-1 : ApoE\&4 } \\
\text { HHV6A } \\
\text { HHV6B } \\
\text { Air Pollutants (PM }{ }_{2.5} \text { and UFPM) } \\
\text { Metals ( Nickel and Vanadium) } \\
\text { Heavy metals (Thallium, Manganese, } \\
\text { Lead) } \\
\text { Trauma : ApoE } \varepsilon 4\end{array}$ & $\begin{array}{l}\text { Deficits in early AD } \\
\text { Increased odor sensitivity threshold } \\
\text { Impaired odor identification } \\
\text { Reduced odor discrimination } \\
\text { Impaired odor memory recall } \\
\text { Reduced odor-evoked potentials }\end{array}$ \\
\hline
\end{tabular}

Legend: Gross anatomy of the nose, the olfactory nerve and the olfactory bulb, reported neuropathology, known pathogenic risk factors, genetics of the host (red) and type of deficits manifests in the early phases of AD. OSN = olfactory sensory neurons, DA = dopaminergic, OT = olfactory tract, PC = piriform cortex, $A M G=$ amygdala, EC = entorhinal cortex, $O F C=$ orbitofrontal cortex, $P M=$ particulate matter with a diameter below $2.5 \mu m$ and $U F P M=$ ultrafine particulate matter.

Alzheimer's disease affects millions of people around the world and the number of cases is increasing. Murphy, in the review, focuses on olfactory dysfunction in AD. Alzheimer's disease is mostly idiopathic, but there are studies showing a genetic predisposition [26].

Currently, there are further studies on the relation between Alzheimer's disease and Down syndrome, mainly due to the development of medicine and the increase in the age of people experiencing this condition. According to Salehi [27] 40-80\% of people with Down syndrome develop symptoms of Alzheimer's disease in the fifth-sixth decade of life.

The criteria for diagnosis in Parkinson's disease (PD) is still questionable. The background is usually idiopathic, with a slight genetic component. The diagnosis is made on the basis of bradykinesia, postural instability, and unintentional and resting tremors. The neuropathology of the disease

is based on the detection of atrophy in the substantia nigra and changes in the level of dopamine in the striatum and the presence of Lewy bodies. As in AD, Parkinson's disease can be detected by anosmia, an early symptom that can precede full motor symptoms by up to a decade [28]. In Rashed's [29] research, they present an olfactory dysfunction in PD as unequivocal hyposmia. The classic staging of PD is the Braak's staging scheme. He suggested that the initial storage of Lewy's bodies starts at the olfactory bulb and anterior olfactory nucleus and then moves to the limbic system a couple of years, before substantia nigra. In a study of patients with newly diagnosed PD, the olfactory dysfunction found is very well seen in the early stages of PD and there are significant decreases in threshold, discrimination, identification after examination smell to certain odors, which makes smell testing very important part in PD patients' diagnosis (Table III).

Table III. Specific Smell deficits on neurodegenerative disease

\begin{tabular}{|c|c|c|c|c|}
\hline \multicolumn{5}{|c|}{ Odor Deficits } \\
\hline $\begin{array}{c}\text { Increased odor } \\
\text { sensitivity } \\
\text { threshold }\end{array}$ & $\begin{array}{c}\text { Impaired odor } \\
\text { identification }\end{array}$ & $\begin{array}{c}\text { Reduced odor } \\
\text { discrimination }\end{array}$ & $\begin{array}{c}\text { Impaired } \\
\text { odor } \\
\text { memory } \\
\text { recall }\end{array}$ & $\begin{array}{c}\text { Reduced odor- } \\
\text { evoked } \\
\text { potentials }\end{array}$ \\
\hline $\begin{array}{c}\text { Decreased } \\
\text { threshold }\end{array}$ & $\begin{array}{c}\text { Decreased } \\
\text { identification }\end{array}$ & $\begin{array}{c}\text { Decreased } \\
\text { discrimination }\end{array}$ & & \\
\hline
\end{tabular}

Alzheimer and Parkinson diseases are the typical and most well known neurodegenerative diseases. We can talk about their relevance to the sense of smell, but they are not the only ones. Other diseases that show symptoms of odor disorders should also be taken into account. Studies have shown that there is another disease of neurodegenerative origin, multiple sclerosis, although immunology is the main cause.

Multiple sclerosis (MS) is a disease of the central nervous system. The immune system attacks the myelin sheath of nerves, weakes the conduction through nerve pathways in the brain and spinal cord, and sends signals to other parts of the body. It provides destruction and decay of axons. The disease is considered to be a multi-stage one with deterioration.

As the symptoms persist, new episodes of clinical worsening may appear with new or exacerbated beats, pain syndromes, and mental symptoms. The disease can be divided into four forms and despite the fact that it is extremely difficult to weaken, it can be managed.

Research has been conducted on the relationship of olfactory dysfunction in MS in addition to the typical symptoms. According to a study done with 
the Sniffin' Sticks test in symptomatic patients suffering from MS, the overall hyposmia score was $27.3 \%$, the perception threshold was $22.3 \%$, discrimination was $13.1 \%$, and odor identification was $30.7 \%$. According to the results of the analysis of the overall indicators, men had a lower median than women, as in discrimination and identification. The odor disturbances of the brain may be caused by neurodegenerative process or by inflamation. In view of the fact that the odor threshold may be the response of the peripheral olfactory part, it may be related to inflammation, discrimination and recognition; the cortex may be affected by neurodegenerative changes [30].

In the ME in which the myelin sheath is diminished, the nerve cells cannot communicate quickly and easily and thus there is a decrease in the stimulus that the brain sends to the sexual organs so that they begin to prepare; in the case of males, with erections, and in females, with the lubrication of the vagina.

\section{Importance de smell-o-meter on the degenerative diseases}

The history of odor measurement comprises many years of research. The first measurements date back to 1850 from simple odor samples to different kind of olfactometers, liquid-gas chromatographs to e-noses, which imitate mammal nose and can detect odors. Odor measurements are important in understanding the human body and the effect of odor on body function and dysfunction.

Analytical tests based on chemical characterizations avoid human errors but are more difficult to measure odors especially in complex compositions and mixtures. If we compare the advantages of the Smell-ometer with the E-nose we see that the latter have the advantage of offering faster results at a lower cost which offers a continuous monitoring of the receptors' odors. However they cannot measure odor intensity and hedonic tone. Neither can they replace dynamic olfactometry, because the odor concentration of the samples must be known to properly train the instrument. [31].

\section{9 - The influence of smell on the psyche}

As it was mentioned at the beginning, the smell affects all our other senses. Thanks to it, we can focus our attention on things that interest us or give up things that do not suit us in some way. The smell affects our well-being. If a certain smell does not suit us, we feel bad, we can be irritated. Various psychological studies show that different people can describe smells differently. One of many types is describing fragrances as colors, we can identify the odor as the color, for example if we smell a lemon we associate it with yellow, rose flower to rose color, grass to green. The state when by stimulation of one sensory pathway leads to feeling it with a different sense is called synesthesia. The most common synesthesia is 'colored hearing', which is why the topic of 'colored' smells is so rare. In the literature, there are cases of association of synesthesia with some forms of autism, but it has not been proven [32].

People have different preferences as to fragrances. It is something that we educate ourselves from an early age, what we are used to, what smells we treat as pleasant. Usually they are smells that we associate with something. That is how stimulating our senses are often used for marketing purpose [33]. For example, at gas stations, to increase coffee sales, the aroma of fresh coffee was added to air fresheners in order to influence the decision by stimulating the sense. Other example can be our comfort while traveling. There are only few studies about odors while traveling by plane. In Yao [34] study, they performed experiment on the Boeing 737 passengers and they were exposed on different scents (lavender, cedar, mandarin) and different pressure in the cabin and time of the experiment. The results were made after answering questions after the experiment, which consist different factors like gender, emotions, comfort. It appears that the scents influenced more men than women, but in the other factors the influence of scent was various, but in all scenarios people scores emotion decreased and it was depending of the flight time.

\section{0 - The influence of fragrance on sex life}

Apart from the influence of a fragrance on our everyday emotions and choices, it also influences our emotional arousal and attractiveness. The sense of smell is associated with people's sexual motivation, as well as with satisfaction and behavior. Our sexual arousal depends largely on sensory arousal. According to the work of Bendas [35] from 2018, referring to many previous sources, people with sensory disorders may suffer from decreased interpersonal interactions and decreased libido. According to Siegel [36] from 2015, people who self-reported reduced sensory feeling reported their negative impact on sexual life, but it did not have a long-term significance. In addition, the patients reporting olfactory disorders initially reported decreased sex drive. This mainly affected men who were depressed after the loss of smell. Bendas, [35] in his work presents the results of a study that was conducted on a group of people to determine the relationship between olfactory and sexuality. The results showed no clear relationship between smell and desire; however, there was a positive relationship between smell and satisfaction. The olfactory sensitivity and its correlation with pleasures were clearer in men, as also in women while having an orgasm.

\section{1 - Personal fragrance - individual fragrance of a person and its variability over the course of life}

Smell is not only the thing that we can receive through our noses but also every human being has its individual smell. It changes through the years. As it was mentioned before, it is strongly observed in children as they can identify the mother's nipples by the smell. Also during growing-up, children evolve through the senses, by distinguishing what they like or not. An individual fragrance and its influence on our lives was a huge impact for many researchers, as well as for marketing.

The studies based on EEGs records show how different fragrances affect spontaneous brain activities and cognitive functions. EEG is also the best way to examine it [37].

The human fragrance can change depending on emotional and physical state. With maturation, the individual's dour changes mainly through the action of hormones. The main organ that produces odors is the skin through the sebaceous glands. The smell itself is not perceptible; the perceptible fragrance is combined with the bacteria on the surface of the skin. Along with maturing, hormone production and growing hair, our scent strengthens, and so does our perception of it. We begin to pay more attention to our own smell, but also to the smell of others, which may determine our choices from friends to partners. A person's personal smell can be influenced by many factors, ranging from social factors, from introduced habits, to changes occurring during the natural aging processes of the organism. In addition, there are studies, such as Allen from 1999, where the relationship of morphological features on the perception of smell has been demonstrated, for example, people with greater facial symmetry are seen as people with more pleasant smell [38]. In a study carried out 20 years ago by Haze [39], changes in human odour depend on age, in the 26-75 age range. During the study, 2 non-aldehyde were distinguished, which was present only in people over 40 years of age. It is the smell that we can recall as "dead cells smell" which we can experience entering the house of some older people. In addition, examination of the skin surface showed the presence of fatty acids and lipid peroxides increasing with age. This showed that our scent becomes more pronounced over time, which is influenced by maturation, development of sebaceous and apocrine skin glands occurs [39]. 
Through the smell, we try to be more attractive, and the smell of others can attract, which has an impact on our behavior. There have been centuries known ways to add other fragrances to enhance or emphasize your fragrance. However, due to individual differences, combining artificial fragrances with the natural body odor is reflected in the form of smells perceived differently. Everyone in their lives has experienced a variety of fragrances and changes depending on who each fragrance is tried on. In older studies, Milinski and Wedekind found a relationship between MHC (major histocompatibility complex) or HLA in humans and the perception of odor associated with one's own odor. By this, they suggest that we choose fragrances to enhance those present in our natural [38].

We try to emphasize our fragrance to make it seem more attractive, but we do it by selecting fragrances individually to match our natural signal. In a 2015 study by Allen, a study was conducted to investigate the effect of fragrance use on distinguishing between individual body odors; it was found that study participants were able to identify odors correctly. At the same time, it was noted that women gave the correct answers more often [38].

The capture of individual smells, pleasant or not, defines our sense of smell, as well as our natural individual fragrance, which depends on the recipient. It identifies us as attractive. Humans are mammals, and as mammals, it is extremely likely that we secrete pheromones. For a long time, the topic of pheromones has been discussed in numerous scientific works concerning their influence on our behavior. Pheromones are special in this respect; it means they are defined as chemical signals that allow communication between individuals of a specific species. These molecules are found in body fluids, specialized exocrine glands, and genital mucous secretions. However, for many years scientists have been wondering if we can sense pheromones. Pheromones are considered important olfactory signals because the signal is transmitted not only to the cortex but also to the limbic system responsible for emotions.

The vomeronasal organ (VNO) is indicated as an important receiver of the pheromone response. There are hypotheses that after a nose injury, such as Le Fort fractures caused by facial trauma, which may damage the VNO, it may result in difficulties in interpersonal relationships, such as choosing partners or in relationships. One of the most important types of pheromones for humans are sex pheromones. The one that potentially attract women in men is androstenon and in women androstenol [41]. Beier suggested that the androgen and estrogen receptors were not present in the armpit glands [42], and free steroids were found in armpit hair. There is a lot of work and experience having been made on the existence and sensation of pheromones, but it is still a subject that is not fully explored. One can take as an example the experiment from 2010 in Brooklyn, where in the art gallery dozens of people gathered to sniff each other's unwashed T-shirts. This was to try to get to know man through smell. Currently, there are perfumes on the market that contain pheromones that are supposed to affect the opposite sex as well as the perception of oneself [43]. Also used as an ingredient in the perfume is copulin, found in vaginal secretions in women, which contains fatty acids with predominated acetic acid.

Knaapila [44] conducted a research on smell within a group of young people, to check if they smelled androstenone. The respondents were required to fill in questionnaires. Trials have shown that women who were able to smell androstenone, those who have had more than one sexual partner in their lifetime, are more pleasant than women who have never had intercourse, which may mean that the sexual experience may affect the perception of the smell.

The connection of sexuality with the sense of smell has its back in history, when it was discovered what benefits can be brought by individual fragrances, named aphrodisiacs, which stimulate other senses and desire. Even then, the possibilities of using oils and perfumes to improve and enhance their smell were discovered, because it became clear that it plays an important role in human sexuality and can evoke strong emotions.

The perception of smell can be a phenomenon referred to as olfactophilia, which is a type of paraphilia, the assumption of which is the feeling of pleasure from smells, also associated with the smells of the human body, including the genitals [45]. It can be understood as a fetish. We can include here an antholagnia, where individuals are sexually aroused by flowers and it may depend on the sight and/or smell of the flowers [46].

Since decades, the properties of fragrances are used, for example, in aromatherapy. Nowadays, it is used for marketing and pleasure.

\section{2 - The SARS-CoV-2 virus}

An undoubted diagnostic challenge at the present time is Covid-19 disease caused by the SARS-CoV-2 virus. For over more than a year, we have been observing the development of the disease, mutations of the virus and the way it affects the human body. The disease presents itself with an acute respiratory failure, cough, high fever, shortness of breath, possibly accompanied by muscle pain, headache.

During the course of the pandemic, new, very characteristic symptoms, often being the only symptoms of the disease, gradually develop. We are talking about the disappearance of taste and smell. People experiencing these effects, described these symptoms as a complete loss of the sense of smell, decrease of it or olfactory disfunction which in some cases takes months to recover, or it did not fully recover from the data we have so far, therefore, we are not able to determine the recovery time.

In the Da Silva work [47], the authors present two pathophysiological hypotheses of loss of smell. One of them is the increased expression of angiotensin 2 receptors (ACE-2) in olfactory epithelial cells as SARS$\mathrm{CoV}-2$ infects humans by binding to ACE-2. Binding to receptors can be used to degenerate epithelial cells leading to inflammation and destruction of receptors responsible for olfaction. The second theory suggests direct changes to the central nervous system, this theory is supported by an experiment in mice during the outline that sars-cov-2 invades the olfactory epithelium when attacking the central nervous system.

The same study also reported data according to which anosmia or hyposmia often affects women, especially those who have fever during an infection. Moreover, the symptoms of a milder course of the disease in women than in men. In Gadi's 2020 paper [48] he presents new factors that could lead to this type of difference. By analyzing the diagram below, the relationship between hormones, immunology and genetics can be seen. They indicate progesterone and estrogen indications for the course of the disease taking into account the milder course of the disease in producing women. Considering immunology, a variety of T-Cells for vaccination in women than in men can be programmed. 


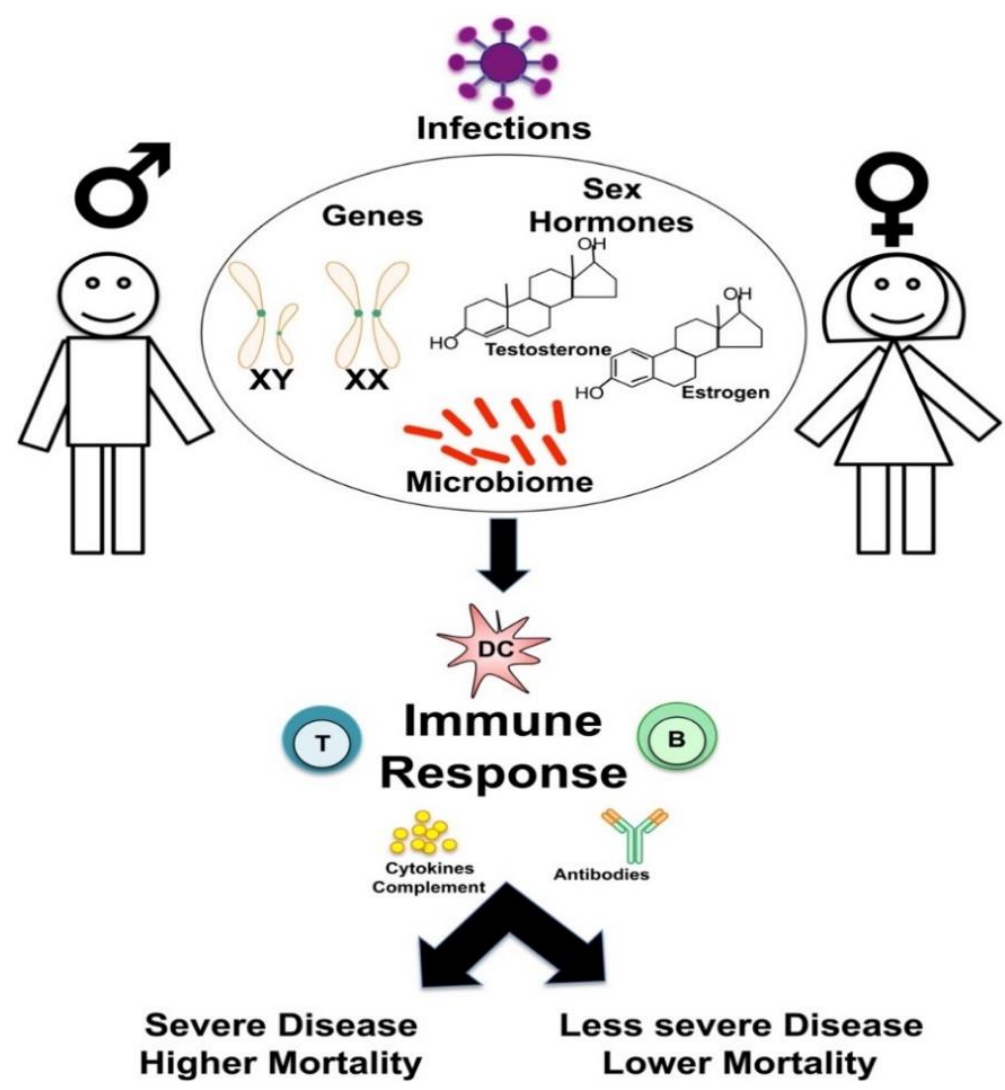

Figure 3. Overview of sex based differences in the immune response to infections [47].

\section{Discussion}

The aim of this study was to introduce and systematize the latest knowledge about the sense of smell and its influence on sensuality and sexuality. We begin with an approximation on the anatomy and physiology of smell to the differences between sex and the impact on the functioning of the body.

When we say "It smells like sex in here" we mean to express our intimate feelings after an intimate life with the people we love the most. The sense of smell is very active in these feelings, both in sexual experiences and in those smells that are linked in one way or another to our lives and to our nearest and dearest ones. But we will not only refer to the body odor that each one of us releases, but also to the one given off by certain elements such as candles, candles, diffusers, fragrances or any other volatile body that is around us and our intimate space.

In reference to the sensory pleasures the sense of smell plays an important role, but sometimes the sense of sight is stronger and more dominant, touch and taste complement perfectly these sensations that send to the brain to process our feelings but many times they are deceptive feelings. However, the sense of smell reaches the brain in a way that the other senses do not. Let us not forget that in the roof of the nostrils there is an accumulation of the olfactory receptor cells of more than 10 million olfactory nerve cells.

The arrival of olfactory nerve stimuli at the peripheral level leads through the central nervous system to the thalamus, but when we really realize that we receive them, they have already been sent to the olfactory area of the brain some time ago. This serves for the reception of certain aromas to stimulate the psyche improving our mood, remembering pleasant situations lived or even to stimulate sexual feelings by reminding us of abstract images, past situations or reactions to certain aromas that will make us feel differently depending on the circumstances.

Mammals secrete so-called pheromones, volatile substances developed by the body to evoke sexual responses in members of their own species. This fact is used by perfumers in humans so that their line of fragrances can be used to excite sensual feelings in human beings. Let us not forget that the smell of sandalwood is very similar to that of androsterol, the human male pheromone. Indole is found in many floral components and simulates our natural body odor. Orange blossom contains indole as a component and can induce an aphrodisiac situation. This fact favors certain fragrance companies to use substances such as lavender, cinnamon, rose or others to establish a sensual climax.

The olfactory membrane in the odor receiving part of both animals and humans plays a very important role in the evaluation of the odor of another of its species. Whether with body odor in humans, or with pheromones in animals and insects. The study of the genetic composition of the immune system plays an important role in the functions of sexual attraction through body odor.

The sense of smell is the one with the most sensual content of all the senses of the human being. Its receptors are very numerous, between 10 and 20 million, only the sense of sight has more, so the sense of smell is very powerful to play the role of sensual engine in the human being. The effect produced by a few drops of perfume before an appointment is known and exploited by many people before going on a date.

Odor losses may be permanent or transitory due to diseases or infectious or viral processes. The effects of smoking or exposure to toxic substances, age, head injuries or degenerative diseases must also be considered. 
It has occurred that certain individuals, driven by sexual passions, come to inhale pheromones due to the advertisements of the perfume industry announcing that their perfumes have an effect on their partners. However, this is not true for three reasons: pheromones are not odors, they cannot be perceived by human beings and third because their olfactory organ does not have the sensory capacity for pheromones.

But there are other considerations to take into account, which are that the perfumes that claim to contain pheromones, these have origin from other animal species, which are only effective for individuals of the same species.

We have already mentioned that pheromones are chemical scents that animals emit naturally and that influence behavior. They have been detected in many living things from moths to dogs, fish and even lobsters. Insects and plants have pheromones, but it is not clear that humans do. The perfume industry is adamant that they do, and they struggle to make their products commercially profitable.

Regarding animals there are many doubts about their performance. A simple detail is that horses and bulls raise their noses when sexually aroused. Observing the behavior of animals and their natural selection gives the feeling that only two types of odor detection have been established. Those that lead to defensive capability, as does the skunk, for example, and those scents that determine to mark the terrain and attract a mate, as do certain animals such as dogs, deer, etc.

Sensuality and sexuality is not the same thing although they are interrelated. The more sensual you are the more sexual you will be. Being sensual means paying attention to and enjoying the senses in their broadest sense, enjoying smells, tastes, sounds, images and tactile sensations. Work, stress, tiredness take us away from perceiving these sense and therefore make us less attentive to sex. But it does not take away from the joy of the simple daily things that our senses perceive.

\section{Conclusion}

In this paper, we tried to collect and accumulate information on the influence of the sense of smell on the sensitivity of the human body through the analysis of recent works and scientific research and based on basic knowledge. Based on the knowledge found, it was possible to extract information that brings us closer to the still not fully discovered relationships that smell exerts on our other senses and on life, as well as how it can determine behavior and predict the occurrence of possible diseases.

By analyzing selected studies and works, we presented the visible differences between sex and the sense of smell in terms of anatomical and physiological aspects. The analysis also included the dependence on age, sexuality, genetics, and the influence of the environment and external factors on the sense of smell. We tried to highlight the difference between what we feel as a smell and what a smell is and its individual differences.

There is a strong link between a fragrance, smell or scent and sexuality, as we have seen. The sense of smell is a powerful mechanism of sexual communication. But not all the smells that surround us can we perceive in a direct way, although it is estimated that the human being can smell a billion different smells. This variety and quantity of smells surpasses the sounds that can be heard or colors that can be seen. We have also seen how body odor itself can give information about age, sex and sexual orientation. The smell of an old man or a child is proof of this.

The effect of Sars-cov-2 on the smell and the relationship between sex, was taken into account.
At the same time, the sense of smell and the understanding of smell are still not fully understood and require a lot of research.

\section{Author Contributions}

Clarós P, Cygan A, Clarós A., wrote the paper. All authors listed have also made substantial, direct, and intellectual contribution to the work, and approved it for publication.

\section{Conflict of Interest Statement}

The authors declare that the research was conducted in the absence of any commercial or financial relationships that could be construed as a potential conflict of interest.

\section{Acknowledgments}

This work was supported by Mr. Salvador Ramon and Clarós Foundation.

\section{References}

1. Appleyard, M. (2019). How Fragrance Affects Our Mood. The Telegraph.

2. The Nasal Cavity. (2021). TeachMeAnatomy.

3. Bradford, A. (2021). Nose: Facts, Function \& Diseases. Live Science.

4. Uzun, A, Ozdemir, F. (2014). Morphometric Analysis of Nasal Shapes and Angles in Young Adults. Brazilian Journal of Otorhinolaryngology; 80 (5): 397-402.

5. Breathe Easy: Nose Shape Was Influenced by Local Climate. Science \& Health. (2017).

6. Ofodile, F A, Bokhari, FJ, Ellis, Ch. (1993). The Black American Nose. Annals of Plastic Surgery;31 (3):209-18. doi:10.1097/00000637-199309000-00002.

7. Gupta, A, Svider, P., Rayess, H., Sheyn. A., Folbe. A., (2017). Pediatric Rhinoplasty: A Discussion of Perioperative Considerations and Systematic Review. International Journal of Pediatric Otorhinolaryngology. 2017; 92:11-16. doi:10.1016/j.ijporl.2016.10.027.

8. Know Your Brain: Olfactory Bulb. Neuroscientifically Challenged. (2018).

9. Hornung, D. (2006). Nasal Anatomy and the Sense of Smell. Hummel T, Welge-Lüssen A (eds). Taste and Smell. An Update. Adv Otorhinolaryngol. Basel, Karger;63:1-22. doi:10.1159/000093747.

10. Meredith, M. (2001). Human Vomeronasal Organ Function: A Critical Review of Best and Worst Cases. Chem. Senses; 26:433445 .

11. Stoyanov, G S, Matev, B K, Valchanov, P, et al. (2018). The Human Vomeronasal (Jacobson's) Organ: A Short Review of Current Conceptions, with an English Translation of Potiquet's Original Text.;10:0. doi:10.7759/cureus.2643

12. Oliveira-Pinto, AV, Santos, RM, Coutinho, RA, Oliveira, LM, Santos, et al. (2014). Sexual Dimorphism in the Human Olfactory Bulb: Females Have More Neurons and Glial Cells than Males.. PLoS ONE; 9(11): e111733. doi:10.1371/journal.pone.0111733

13. Zhang, X, Chen, W, Li S, Zhou, W. (2017). Developmental Finetuning of Human Olfactory Discriminability. Chem Senses;42(8):655-662. doi:10.1093/chemse/bjx047.

14. Nováková, L, Plotěná, D, Havlíček, J. (2017). Age and Pubertal Status-Related Changes in Reports of Perception of Personal Odors. Perception; 46(3-4):484-97. doi: $10.1177 / 0301006616686096$.

15. Caruso, S, Grillo, C, Agnello, C, Maiolino, L, (2001) A prospective study evidencing rhinomanometric and 
olfactometric outcomes in women taking oral contraceptives. Human reproduction;16(11):2288-2294 doi:10.1093/humrep/16.11.2288.

16. Renfro, K J, Hoffmann, H. (2013). The Relationship between Oral Contraceptive Use and Sensitivity to Olfactory Stimuli. Hormones and Behavior; 63(3):491-96. doi:10.1016/j.yhbeh.2013.01.001.

17. Schaefer, M., Iravani, B., Arshamian, A., \& Lundstrom, J. N. (2021). No evidence that hormonal $€$ contraceptives affect chemosensory perception. i-Perception.; 11(6), 1-13. doi:10.1177/ 2041669520983339

18. Lundström, J N, McClintock, M K, Olsson, M J. (2006). Effects of Reproductive State on Olfactory Sensitivity Suggest Odor Specificity. Biological Psychology.;71 (3):244-47. doi: 10.1016/j.biopsycho.2005.07.001

19. Kollndorfer, K, Ohrenberger, I, Schöpf, V. (2016). Contraceptive Use Affects Overall Olfactory Performance: Investigation of Estradiol Dosage and Duration of Intake. PLoS ONE; 11(12): e0167520.

20. Dikici, O, Bayar Muluk, N, Sahin E, Altintoprak, N. (2017). Effects of pregnancy on olfaction. ENT Updates; 7(2):104-107. doi:10.2399/jmu.2017002009.

21. Fornazieri, M.A., Prina, D.M.C., Favoreto, J.P.M. et al. (2019). Olfaction During Pregnancy and Postpartum Period. Chem. Percept. ; 12:125-134.

22. Sorokowska A, Schriever V. A, Gudziol V, Hummel C, Hähner A, Iannilli E, et al. (2015). Changes of olfactory abilities in relation to age: Odor identification in more than 1400 people aged 4 to 80 years. European archives of Oto-rhinolaryngology. 2015; 272(8):1937-1944. doi:10.1007/s00405-014-3263-4

23. Ros, C, Alobid, I, Centellas, S, Balasch, J, Mullol, J, CasteloBranco, C. (2012). Loss of smell but not taste in adult women with Turner's syndrome and other congenital hypogonadisms.

24. Maturitas.; 73:244-250. doi.org/10.1016/j.maturitas.2012.07.012

25. Terasawa, E, Kurian, J. (2012). Neuroendocrine Mechanism of Puberty. Ch. 19. In: Handbook of Neuroendocrinology, ed. by G. Fink, D W. Pfaff, J E. Levine. Elsevier.; 43384.doi.org/10.1016/B978-0-12-375097-6.10019-8

26. Bathini P, Brai E, Auber LA. (2019). Olfactory dysfunction in the pathophysiological continuum of dementia. Ageing Res. Rev.; 55. doi:10.1016/j.arr.2019.100956

27. Murphy C, Jernigan TL, Fennema-Notestine C. (2003). Left hippocampal volume loss in Alzheimer's disease is reflected in performance on odor identification: a structural MRI study. J Int Neuropsychol Soc ; 9(3):459-471.

28. Salehi A, Wesson Ashford J, Mufson, E J. (2016). The Link between Alzheimer's Disease and Down Syndrome. A Historical Perspective". Curr Alzheimer Res; 13 (1):2-6. doi.org/10.2174/1567205012999151021102914.

29. Ubeda-Bañon, I., Saiz-Sanchez, D., Flores-Cuadrado, A. et al. (2020). The human olfactory system in two proteinopathies: Alzheimer's and Parkinson's diseases. Transl Neurodegener; 9 (22). doi.org/10.1186/s40035-020-00200-7

30. Rashed, K.H., Bahnasy, W.S., El-Heneedy, Y.A.E. et al. (2020). Patterns of olfactory dysfunctions in patients with Parkinson disease. Egypt J Neurol Psychiatry Neurosurg; 56 (73).

31. Bsteh G, Berek K, Hegen H, et al. (2020). Smelling multiple sclerosis: Different qualities of olfactory function reflect either inflammatory activity or neurodegeneration. Multiple Sclerosis Journal.; 26(1):57-68. doi:10.1177/1352458518814113

32. Clarós P, Dąbkowska A, Clarós A,.Portela A, Pérez R, et.al. (2021). State of the art olfactometers. Different types. Journal of
Bioscience \& Biomedical Engineering. Volume 2 Synthesesia. Wikepedia.

33. King, G F. (2018). Your Sense of Smell Controls What You Spend and Who You Love. From our Series. Ideas.

34. Yao, X, Song Y, Vink P. (2021). Effect of scent on comfort of aircraft passengers. Work; 68(s1):S273-S280. doi: 10.3233/WOR-208025.

35. Bendas, J., Hummel, T, Croy, I. (2018). Olfactory Function Relates to Sexual Experience in Adults. Arch Sex Behav; 47:1333-1339. doi.org/10.1007/s10508-018-1203-x

36. Siegel, J ., Kung S Y, Wroblewski K E, Kern D W, McClintock M K, (2021). Olfaction Is Associated With Sexual Motivation and Satisfaction in Older Men and Women. The Journal of Sexual Medicine; 18(2): 295-302. doi.org/10.1016/j.jsxm.2020.12.002

37. Kandhasamy S, Kim S. (2016). Influence of Fragrances on Human Psychophysiological Activity: With Special Reference to Human Electroencephalographic Response. Scientia Pharmaceutica.; $84 \quad$ (4):724-52. doi.org/10.3390/scipharm84040724.

38. Allen C, Havlíček J, Roberts S C. (2015) Effect of fragrance use on discrimination of individual body odor. Front. Psychol. doi.org/10.3389/fpsyg.2015.01115.

39. Haze S, Gozu Y, Nakamura S, Kohno Y, Sawano K. (2001). 2Nonenal Newly Found in Human Body Odor Tends to Increase with Aging. Journal of Investigative Dermatology.; 116 (4): 520 24. doi.org/10.1046/j.0022-202x.2001.01287.x

40. Milinski, M. Wedekind C. (2001). Evidence for MHC-correlated perfume preferences in humans". Behavioral Ecology; 12(2):140149. doi.org/10.1093/beheco/12.2.140.

41. Taymour M, El Khouly G, Hassan A. (2011). Pheromones in Sex and Reproduction: Do They Have a Role in Humans?. Journal of Advanced Research; 3(1):1-9. doi.org/10.1016/j.jare.2011.03.003.

42. Beier, K., Ginez, I. Schaller, H. (2005). Localization of steroid hormone receptors in the apocrine sweat glands of the human axilla. Histochem Cell Biol; 123, 61-65. doi.org/10.1007/s00418-004-0736-3

43. Riley A. (2016). Pheromones Are Probably Not Why People Find You Attractive.

44. Knaapila A, Tuorila H, Vuoksimaa E, Keskitalo-Vuokko K, Rose R J, (2012). Pleasantness of the Odor of Androstenone as a Function of Sexual Intercourse Experience in Women and Men. Archives of Sexual Behavior.; 41(6): 1403-1408. doi.org/10.1007/s10508-011-9804-7

45. Griffiths M. (2019). The Science of Sex and Smell. Psychology Today.

46. Griffiths M. (2017) Making Scents of It All: A Brief Look at Sex, Smell and Olfactophilia..

47. Da Silva Júnior, P R, Gomes, A L O R , Coelho, L E A. et al. (2021). Anosmia and COVID-19: perspectives on its association and the pathophysiological mechanisms involved. Egypt J Neurol Psychiatry Neurosurg; 57(8). doi.org/10.1186/s41983-02000266-0

48. Gadi N, Wu S, P. Spihlman A, Moulton V R. (2020). What's Sex Got to Do With COVID-19? Gender-Based Differences in the Host Immune Response to Coronaviruses. Front. Immunol; doi.org/10.3389/fimmu.2020.02147 